\title{
OPORTUNIDADES, ESCOLHAS E VOCAÇÃO: PERCURSOS NA CONSTITUIÇÃO DO 'SER PROFESSOR' DE DOCENTES BACHARÉIS DO ENSINO SUPERIOR PRIVADO
}

\author{
Opportunities, Choices and Vocation: Ways in the Formation Process of 'Being a \\ Teacher' in Bachelor Courses in Private Higher Education
}

\author{
Lígia Vieira da Silva Cavalcante ${ }^{1}$ \\ Suzana Feldens Schwertner ${ }^{2}$
}

\begin{abstract}
Resumo: O presente artigo apresenta os resultados de uma pesquisa realizada com professores bacharéis que atuam no ensino superior e tem como objetivo conhecer como se deu o percurso que conduziu esses profissionais à docência. Trata-se de pesquisa qualitativa, realizada por meio de entrevistas semiestruturadas com oito professores que atuam em uma Instituição de Ensino Superior da rede privada, no interior do estado do Ceará. As entrevistas foram analisadas através da proposta de Análise de Conteúdo. Os resultados apresentam, inicialmente, que as escolhas dos docentes pela área de formação aconteceram de forma aleatória ou por influência dos familiares. Contudo, no transcorrer da graduação conseguiram uma identificação com os cursos escolhidos e se sentem realizados com a sua atuação como professores. Relataram que, durante a graduação, as atividades de monitoria, pesquisa e identificação com determinadas disciplinas e professores os fizeram vislumbrar a docência como campo de atuação. Para que pudessem lecionar ou se sentirem mais preparados para o exercício da docência, trilharam alguns caminhos formativos a partir da graduação: cursar pós-graduação foi a escolha da maioria dos entrevistados. No entanto, referiram que as disciplinas das especializações e dos mestrados lhes trouxeram conhecimentos específicos de área, mas pouco contribuíram para a sua formação docente. Ao propor conhecer esta amostra de professores bacharéis, espera-se que o presente estudo contribua para a reflexão sobre a formação docente e indique caminhos para (re)pensar a prática profissional docente.
\end{abstract}

Palavras-chave: Formação docente. Professores bacharéis. Ensino superior privado.

Abstract: This paper presents the results of a survey conducted with bachelor professors who work in higher education and aims to understand the path which led these professionals to become teachers. This research, defined as a qualitative one, was carried out through semistructured interviews with eight teachers who work in a private Higher Education Institution in the countryside of Ceará, a state in the northeast of Brazil. These interviews were analyzed using the Content Analysis method. The results show, initially, that teachers' choices for their

\footnotetext{
${ }^{1}$ Possui graduação em Serviço Social pela Universidade Estadual do Ceará (2011), especialização em Serviço Social, Seguridade Social e Legislação Previdenciária pela Faculdade Ratio (2014) e mestrado acadêmico em Ensino pela Universidade do Vale do Taquari (Univates) (2020). É professora e coordenadora do curso de bacharelado em Serviço Social da Faculdade Princesa do Oeste (FPO). Orcid: https://orcid.org/0000-0002-73608477. E-mail: ligia.vieirasc86@gmail.com.

${ }^{2}$ Possui graduação em Psicologia pela Universidade Federal do Rio Grande do Sul (2001), mestrado em Educação pela Universidade Federal do Rio Grande do Sul (2005), doutorado em Educação pela Universidade Federal do Rio Grande do Sul (2010) e pós-doutorado em Educação pela Universidade Federal do Rio Grande do Sul (2011). É professora do curso de Psicologia da Universidade do Vale do Taquari (Univates) e docente do Programa de Pós-Graduação em Ensino (Univates). Orcid: https://orcid.org/0000-0002-2913-9191. E-mail: suzifs@ univates.br.
} 
specific training area happened randomly or under the influence of family members. However, during their undergraduate courses, they managed to identify themselves with the chosen areas and felt accomplished with their professions. The participant teachers reported that, during their undergraduate courses, monitoring, research and other activities with certain disciplines and professors made them see teaching as a professional field. Thus, in order to teach or feel more prepared for real teaching, they followed some training paths from undergraduation. Attending postgraduate studies was the choice of most participants. However, they mentioned that the disciplines of specialization and master courses brought them specific knowledge in the area, but contributed little to their teacher training. By proposing to know this sample of graduate professors, it is expected that this study will contribute to the reflection on teacher education and indicate ways to (re)think teaching practice.

Keywords: Teachers formation. Bacharel professors. Private higher education.

\section{Introdução}

A educação de nível superior tem sido reconhecida como fundamental para o desenvolvimento político, tecnológico e cultural da nação, conforme explicitado, de forma geral, no artigo 205 da Constituição Federal (BRASIL, 1988), e, de forma mais específica, no artigo 43 da Lei de Diretrizes e Bases da Educação Nacional (LDB), de nº 9.394/96 (BRASIL, 1996). Ela se apresenta como necessária e importante para o desenvolvimento humano, na qualificação dos indivíduos para o trabalho e para o exercício pleno da cidadania.

Para que aconteça a educação na forma preconizada pela Carta Magna vigente, é necessária a liberdade de aprender, ensinar, pesquisar e divulgar o pensamento, a arte e o saber. Os professores, notadamente do Ensino Superior, tornam-se agentes responsáveis pelo atendimento ao chamado das nossas legislações, devendo, para tanto, apropriarem-se permanentemente do conhecimento, realizando as atividades firmadas no tripé ensino, pesquisa e extensão, em consonância com as exigências sociais atuais e futuras.

De acordo com a LDB, a preparação do professor para atuar como docente no Ensino Superior deverá se fazer em nível de pós-graduação, com prioridade para programas de mestrado e doutorado, mas sendo permitida, na ausência desses, aqueles cuja formação é oriunda dos cursos lato sensu, que confiram título de especialização em determinada área (BRASIL, 1996).

Sabemos, contudo, que determinadas especializações não compreendem uma formação pedagógica, propiciando que encontremos nas Instituições de Ensino Superior (IES) professores que têm graduação e pós-graduação em áreas que não os capacitam para a docência. São profissionais sem formação específica na área de licenciatura, que não possuem didática no exercício da docência e que, por vezes, exercem a docência simultaneamente com suas atividades profissionais.

Morosini (2000) relata que encontramos professores exercendo a docência universitária com formação didática obtida em cursos de licenciatura; outros, que trazem sua experiência profissional para a sala de aula; e, ainda, aqueles sem experiência profissional ou didática, advindos de curso de especialização e/ou programas stricto sensu.

A fala de Anastasiou (2015, p.17) reforça esse entendimento, ao afirmar que:

[...] nem sempre encontramos atuando como docentes pessoas que puderam se preparar sistematicamente para exercer essa profissão tão desafiante, que exige mediar o conhecimento científico necessário à formação profissional, com os dados da 
realidade e com o funcionamento cerebral e a capacidade de abstração e volição do estudante universitário, superando formas seculares de transmissão de informações na universidade.

Entendemos que conhecer a trajetória de escolha da área de formação e os caminhos percorridos para o exercício da docência possibilita identificar não só os percursos trilhados pelos bacharéis, mas as lacunas presentes em sua formação inicial e continuada e as reverberações dessa formação nas práticas adotadas no contexto da sala de aula.

Assim, conhecer o desenvolvimento profissional docente, suas potencialidades e seus entraves, poderá indicar caminhos para (re)pensar a formação continuada e a docência, repensando a importância desses profissionais diante de sua contribuição no processo de formação de outros profissionais. Poderá, também, sinalizar ações a serem adotadas pelos professores e pelas IES empregadoras, para viabilizar o acesso a programas de formação permanente, abrindo caminhos para o aperfeiçoamento profissional, a promoção de um ensino de qualidade e a transformação social.

Diante do exposto, buscamos então investigar como se constituiu a trajetória da formação e a trajetória profissional de professores que atuam em cursos de bacharelado de uma IES privada no interior do estado do Ceará.

Este artigo se encontra organizado da seguinte maneira: primeiramente, apresentamos algumas considerações sobre quem é o professor do Ensino Superior e o que se espera dele; em seguida, abordamos o percurso metodológico da pesquisa, apresentando o seu lócus, a caracterização quanto ao modo de abordagem, os sujeitos, os instrumentos utilizados para a coleta dos dados, bem como a metodologia de sua análise; na sequência, apresentamos os resultados e discussões da investigação. Por fim, seguem as considerações finais e as referências.

\section{Professor do ensino superior: quem é e o que se espera dele?}

Temos vivenciado um período de expressivas alterações no Ensino Superior. Houve uma democratização e expansão das instituições que ofertam essa modalidade de ensino, concomitantemente ao aumento das vagas para o ingresso de alunos, que se apresentam de forma bastante heterogênea.

E é a expressiva expansão dessa modalidade de ensino, com todas as características que lhe são peculiares, que se torna o palco para a atual discussão da necessidade da contínua qualificação do professor que atua nesse contexto. Requer-se uma atuação competente do professor do Ensino Superior para a formação dos alunos em futuros profissionais, que estejam aptos a desenvolverem as atividades requeridas socialmente.

Mas, e quem é esse professor? Franco (2000) apresenta uma elucidação muito pertinente para essa indagação, tratando de responder quem ele é a partir de cinco pontos de vista: situacional, institucional, político, profissional e do avanço do conhecimento. Sob o primeiro parâmetro, o situacional, a autora refere que o professor do Ensino Superior é aquele que trabalha na grande e complexa universidade, com um sólido sistema de pós-graduação e com consolidados grupos de pesquisa. Mas é também aquele que trabalha na IES isolada, na qual o ensino é a própria razão de ser. É o que trabalha na universidade orientada para o mercado, assim como o que atua na instituição comunitária ancorada no seu meio.

Franco (2000), olhando o professor sob o ponto de vista institucional, afirma que é aquele cujo plano de trabalho dispõe de horários para a pesquisa, mas é também aquele cujas 
horas de ensino são tão elevadas que não lhe sobra tempo para investigações e, por vezes, nem para preparar as suas aulas. Do ponto de vista político, pode ser definido como o que vive as tensões da própria área de conhecimento, esta impregnada, muitas vezes, de corporativismo, acrescidas das tensões das demais áreas na luta por espaços e financiamentos.

Tomando como horizonte o campo profissional, é o que privilegia a universidade como espaço de trabalho, mas que também está inserido em determinado contexto profissional com suas demandas específicas. É o que vê seu aluno como impulsionador do trabalho, mas também como futuro concorrente em um mercado recessivo. É aquele profissional em contínua avaliação, desde o ingresso na carreira, por meio de concursos, de avaliações sistemáticas de ascensão profissional, de participação em eventos e submissão de trabalhos, de apresentação de projetos para financiamento e de relatórios de atividades e de pesquisa. Por fim, sob o ponto de vista do avanço do conhecimento, o professor é aquele que se insere no processo produtivo que perfaz o avanço, de alguma forma colaborando para isso, mas é também o que dissemina referido avanço (FRANCO, 2000).

Assim, segundo a análise de Franco (2000), ser professor do Ensino Superior é abarcar algumas ou todas essas requisições. É trabalhar em uma ou mais IES, seja pública ou privada, e ainda ter outro vínculo empregatício, desenvolvendo atividades relacionadas a sua área de formação. É desenvolver múltiplas tarefas e enfrentar diferentes tensões no cotidiano profissional. É buscar múltiplos caminhos que auxiliem a construção do conhecimento junto aos seus alunos.

Esse professor assume grandes responsabilidades na educação e na formação profissional de seus alunos, no sentido de proporcionar uma formação crítica e capacitá-los para enfrentar os desafios do mundo moderno. Para Anastasiou (2004), saber-se docente universitário é saber-se parte de uma categoria profissional que tem a aula como espaço privilegiado na relação com os alunos, estabelecendo processos de parceria na conquista, tradução, construção, aplicação e sistematização de diferentes saberes, possibilitando a formação de profissionais que atuarão na realidade, construindo-a e transformando-a, ao mesmo passo em que se constroem e se transformam.

Acreditava-se que o professor, ao terminar seu curso superior, já estava preparado para lecionar a sua disciplina. Pensava-se, também, que ele conseguiria transmitir todos os conteúdos que aprendeu durante a sua graduação. No entanto, os estudos evoluem tão velozmente que esses profissionais, para se sentirem seguros e aptos para ensinar, são obrigados a estar continuamente aprendendo (GIL, 2012).

O docente, ao assumir o compromisso de que sua atuação esteja além da simples reprodução de informações, que busque agir de forma reflexiva, crítica e competente, que contribua significativamente no percurso formativo dos estudantes, ver-se-á impelido a buscar uma contínua formação, que the possibilite conhecimentos e habilidades para conduzir processos de ensino e de aprendizagem significativos.

Frente a essas requisições, merece destaque o fato de que as legislações brasileiras não contemplam a exigência da formação docente que abarque os saberes relacionados às práticas pedagógicas, de pesquisa e extensão, além do conhecimento específico de sua área. A Constituição Federal (BRASIL, 1988) é a legislação máxima do nosso país, contemplando algumas indicações sobre a educação enquanto direito social; contudo, é na LDB (BRASIL, 1996) que a discussão a respeito da formação do professor será abordada, ainda que de forma parca. 
Para os professores da educação básica (pré-escola, ensino fundamental e ensino médio), há artigos na LDB que identificam a obrigatoriedade da formação inicial, continuada e o domínio pedagógico desses profissionais, além de indicarem o poder público como responsáveis pelo provimento de tais requisitos. Já os professores que atuam no Ensino Superior, são mencionados no artigo 66 da LDB, que apresenta a seguinte redação: "[...] a preparação para o exercício do magistério superior far-se-á em nível de pós-graduação, prioritariamente em programas de mestrado e doutorado" (BRASIL, 1996, p. 27). Quanto aos requisitos sobre sua formação didática, a legislação não apresenta nenhuma indicação ou exigência, subentendo que a formação inicial (bacharelado ou licenciatura) atrelada a algum curso de pós-graduação (especialização, mestrado ou doutorado) já confere a capacidade para o exercício da docência.

Masetto (2012) refere que, apesar da importância de o professor universitário ter domínio na área pedagógica, o referido ponto é o mais carente quando analisamos a docência no nível superior. Segundo o autor, isso ocorre ou porque os professores nunca tiveram a oportunidade de aproximação com essa temática ou porque a veem como algo supérfluo ou desnecessário para sua atividade de ensino.

Com efeito, as legislações e políticas que abordam a atuação docente no Ensino Superior não apresentam uma exigência de formação que contemple saberes específicos da docência, relacionados aos processos de ensino e de aprendizagem, avaliação, planejamento, etc. Contudo, as pesquisas demonstram que o professor precisa, para além da formação em sua área específica, ter formação pedagógica que lhe permita transformar suas práticas docentes, investindo em metodologias de ensino que visem uma aprendizagem significativa, que propicie uma formação profissional capaz de atender às novas demandas postas socialmente.

De acordo com Lira e Sponchiado (2012, p. 8):

Para exercer a profissão de docente do ensino superior, não basta ter apenas a formação na área específica; é preciso buscar incessantemente o aprendizado e saberes necessários à prática educativa, juntamente com valores éticos e morais, formando, assim, cidadãos capazes de produzir e construir sua própria identidade, isto é, ensinar e aprender com competência pedagógica.

Os escritos de Almeida (2012) corroboram com esse entendimento quando afirmam que a docência universitária é entendida como uma prática complexa, que irá requerer leituras culturais, políticas e pedagógicas a respeito dos objetos de ensino, dos contextos e sujeitos envolvidos. Contrariando o pensamento comum, que por vezes paira no ambiente acadêmico, a ação de ensinar carrega muitos desafios e requer respostas complexas: ensinar como estudar, como aprender, como questionar e como se organizar são, também, atribuições demandadas aos docentes.

A docência, compreendida dentro de um aspecto tradicional, é tida como o agir do professor, que ensina a partir das inspirações na forma como foi ensinado por seus professores. O preparo desses profissionais permaneceu, durante muito tempo, focalizado exclusivamente no domínio de conteúdo. Acreditava-se que aquele que detém conhecimento sabe ensinar, indicando que o domínio de conteúdo é o suficiente para o exercício da docência.

Uma sólida formação inicial é indispensável para assumir a docência, contudo mostrase insuficiente se não for vinculada aos saberes e competências pedagógicas. O domínio dos conteúdos específicos e pedagógicos propiciará processos de ensino e de aprendizagem significativos para professor e aluno, constituindo práticas eficazes na formação de profissionais e cidadãos críticos e conscientes. 
Para Masetto (2012, p. 15), o professor do Ensino Superior precisa se conscientizar do seu papel de docente, que, como o exercício de qualquer profissão, exigirá capacitação própria e específica, e não se restringe a ter diploma de bacharel, de mestre ou doutor, ou exercer determinada profissão. $\mathrm{O}$ autor afirma que:

Exige isso tudo e competência pedagógica, pois ele é um educador, alguém que tem
a missão de colaborar eficientemente para que seus alunos aprendam. Esse é o seu
ofício e compromisso. Para se desempenhar bem esse papel, o professor necessita de
uma formação pedagógica.

Anastasiou (2005), a partir de pesquisas realizadas, verificou que, com exceção dos docentes provenientes das Licenciaturas e Pedagogia, a maioria dos professores do Ensino Superior não conta com a formação necessária à construção de uma identidade profissional para a docência. Embora estejam em sala, lecionando, nem sempre os professores dominam as condições necessárias para atuar como profissionais docentes.

A ausência de uma formação pedagógica pode trazer implicações para o exercício da docência. Por isso, torna-se necessária e urgente a reflexão sobre a formação dos professores, principalmente daqueles que não tiveram contato com uma formação pedagógica durante sua formação inicial e também no transcorrer dos anos do exercício docente.

\section{Metodologia}

Nesta seção é apresentada a trajetória metodológica percorrida para a realização desta pesquisa, cujo objetivo foi conhecer como se deu o percurso que conduziu professores bacharéis à docência e as ressonâncias de suas escolhas nos processos de ensino e de aprendizagem.

A pesquisa seguiu a abordagem qualitativa, que, segundo Minayo (2015), é aquela que trabalha com um nível de realidade social que não pode ou não deve ser quantificado. Ou seja, trabalha com o universo dos significados, dos motivos, das aspirações, das crenças, dos valores e das atitudes. Ainda segundo a autora, a pesquisa qualitativa busca então "[...] compreender relações, valores, atitudes, crenças, hábitos e representações e a partir desse conjunto de fenômenos humanos gerados socialmente, compreender e interpretar a realidade" (MINAYO, 2015, p. 24).

Diante do objetivo desta pesquisa, entendemos a abordagem qualitativa como a que melhor respondeu ao proposto. Essa abordagem não se preocupa em quantificar, mas em compreender e explicar a dinâmica das relações sociais que permeia a vida e o fazer profissional de tais docentes, valorizando suas falas, suas crenças, seus valores e suas atitudes.

$\mathrm{O}$ instrumento escolhido e utilizado para coleta de dados foi a entrevista semiestruturada. Nesse tipo de entrevista, o entrevistador se guia por um roteiro, em que as perguntas são previamente estabelecidas, mas sem oferecer ao entrevistado alternativas de resposta, propiciando que ele as responda livremente (GIL, 2019).

O lócus da pesquisa foi uma Instituição de Ensino Superior, da rede privada, localizada em Crateús, interior do estado do Ceará. Foram selecionados oito docentes, tendo como critério de inclusão ser bacharel e lecionar há pelo menos três semestres na IES. Foram escolhidos dois professores bacharéis em Direito, dois bacharéis em Enfermagem, dois bacharéis em Psicologia e dois bacharéis em Serviço Social, concedendo uma representatividade paritária entre os cursos oferecidos pela IES. Visando também uma representatividade no tocante ao gênero, foram selecionados, por curso, um docente do sexo masculino e uma do sexo feminino. 
A pesquisa seguiu as diretrizes e normas previstas na Resolução n. ${ }^{\circ} 466 / 2012$ e n. ${ }^{\circ}$ 510/2016, ambas do Conselho Nacional de Saúde, tendo sido encaminhada ao Comitê de Ética em Pesquisa da Univates e recebido parecer favorável com CAAE de número 30630720.0.0000.5310.

As entrevistas aconteceram entre os dias 20 de agosto e 04 de setembro de 2020, de forma virtualizada, através do Google Meet, que é um serviço de comunicação gratuito, de videochamada, ativado mediante conexão com internet. Os participantes concederam sua anuência através da assinatura do Termo de Consentimento Livre e Esclarecido (TCLE). Foi solicitada a autorização para gravar a entrevista e não houve nenhuma objeção dos professores. Visando preservar a identidade dos participantes, a identificação dos mesmos se deu pelo uso da letra 'P' acrescida de um numeral.

O roteiro utilizado para as entrevistas foi composto de dez questões abertas, que versavam sobre as escolhas pela área de formação, os caminhos que os conduziram à docência, as práticas pedagógicas e como acontece o processo de formação continuada, com destaque para as dificuldades e possibilidades. Foram elencadas, ainda, sugestões a serem adotadas pela IES para viabilizar e potencializar a formação continuada.

Os dados transcritos e validados pelos entrevistados foram organizados utilizando a análise de conteúdo proposta por Bardin (2011). Para a autora, “[...] a análise de conteúdo aparece como um conjunto de técnicas de análise das comunicações que utiliza procedimentos sistemáticos e objetivos de descrição do conteúdo das mensagens" (BARDIN, 2011, p. 44). A referida análise se organiza em torno de três fases: 1) pré-análise; 2) exploração do material; 3 ) tratamento dos resultados, inferência e interpretação.

Entende-se que a análise de conteúdo proporcionou um estudo profundo e cuidadoso dos dados levantados e se constituiu como uma ferramenta apropriada de interpretação das percepções dos professores entrevistados, permitindo compreender, neste estudo, as escolhas e os caminhos percorridos para a sua constituição enquanto docente bem como da forma em que repercutiram na totalidade das suas vidas, para além da sala de aula. Os dados coletados e analisados estão sistematizados a seguir.

\section{Narrativas de professores bacharéis sobre formação profissional e docência}

Ao pensarmos a docência como espaço de atuação profissional, a mesma parece ser uma escolha um tanto evidente para aqueles que advêm dos cursos de licenciatura, pois é um nível de formação direcionada para quem pretende lecionar. Já para os concluintes dos cursos de bacharelado, nem sempre a docência aparece como uma escolha inicial, pois a formação do bacharel o capacita para exercer as atividades profissionais atreladas a sua área de conhecimento. Para os bacharéis, a docência poderá ser exercida no Ensino Superior, desde que os mesmos tenham alguma formação em nível de especialização, mestrado ou doutorado.

Analisando a particularidade da IES investigada, na oferta do primeiro semestre de 2020, a mesma apresentava o quadro docente composto por cinquenta e sete professores, cuja maioria é de bacharéis enfermeiros, assistentes sociais, psicólogos e advogados. Contava também com alguns licenciados das áreas de Filosofia, Sociologia, História, Biologia e Letras. As titulações variavam entre especialistas, mestres e doutores.

No Quadro 1 está o perfil dos professores entrevistados. 
Quadro 1 - Perfil dos docentes entrevistados

\begin{tabular}{|c|c|c|c|}
\hline Código & Sexo & Área de Formação & Titulação \\
\hline P1 & Feminino & Bacharelado em Direito & Mestre \\
\hline P2 & Masculino & Bacharelado em Direito & Mestre \\
\hline P3 & Feminino & Bacharelado em Enfermagem & Mestre \\
\hline P4 & Masculino & Bacharelado em Enfermagem & Mestre \\
\hline P5 & Feminino & Bacharelado em Psicologia & Mestre \\
\hline P6 & Masculino & Bacharelado em Psicologia & Mestre \\
\hline P7 & Feminino & Bacharelado em Serviço Social & Especialista \\
\hline P8 & Masculino & Bacharelado em Serviço Social & Mestre \\
\hline
\end{tabular}

Fonte: elaborado pelas autoras, 2020.

Considerando que os participantes desta pesquisa são todos bacharéis, com áreas de formação em Direito, Enfermagem, Psicologia e Serviço Social e que muitos deles exercem atividades laborais na área de formação concomitante à docência, acredita-se ser importante iniciarmos relatando como aconteceram as escolhas pela área de formação. Para muitos deles, a escolha se deu de forma aleatória, ou pela influência dos familiares, ou ainda mediante pressão para ingressar no Ensino Superior, independentemente de qual curso seria:

[...] eu não queria Direito, não era minha opção, nunca foi na verdade [...] Minha opção era Medicina. [...] eu só fiz Direito por influência da minha mãe [...] porque era o sonho dela. [...] [P1].

[...] a escolha pela enfermagem surgiu mediante [...] minha família [...] principalmente também pela minha religião, em saber que muitos santos católicos, eles foram enfermeiros. [...] tudo isso fez com que eu escolhesse a minha formação, pela minha formação católica e também está ligado a querer ajudar as pessoas [P4].

[...] a minha graduação foi bem aleatória. [...] eu estava tentando passar no vestibular por uma pressão dos pais [...] fiz vestibular de administração, não passei. Depois tentei outro vestibular, não passei [...] aí fui e fiz Serviço Social, porque era 'fácil de passar', digamos assim, comparado ao Direito, à Medicina [...] [P8].

Eu sou psicólogo de formação, não foi a primeira escolha. Eu já fiz faculdade de Direito, [...] de Biologia, já fui aprovado num curso de Medicina, mas não cheguei a ir [...]. Sempre foi muito confuso para mim a relação entre as Ciências Sociais e as Ciências Biológicas. [...] até que sem saber muito bem o que era Psicologia, eu achei que a Psicologia era o meio termo entre as Ciências Sociais e as Ciências Biológicas [P6].

Mesmo muitos dos cursos não tendo sido a escolha inicial dos profissionais, todos demonstraram que são realizados com as suas formações. A escolha em permanecer e concluir a graduação aconteceu, para alguns, através da identificação com o curso no transcorrer dos semestres, mediante conversa com alguns professores e aproximação com determinadas disciplinas, como é possível verificar nas seguintes falas: 
[...] quando eu cheguei no terceiro semestre de Direito, eu olhei assim na matéria, que é a matéria que hoje eu ministro [...], e eu disse assim: é isso que eu quero! O que é que eu quero na Medicina? Eu quero é Direito! Eu gosto é disso aqui! [P1].

[...] por questões pessoais eu precisei me afastar no segundo semestre. Um dia eu fui na [nome da universidade] [...] e encontrei uma professora e ela disse: [...] 'peça readmissão de abandono, você tem tudo para ser uma assistente social'. E aí eu pedi um tempo dessa professora, nós tomamos um café e ela foi me dizer tudo. E eu fiquei assim, encantada, com o que ela dizia, eu me via naqueles espaços fazendo aquilo [...]. E eu disse: eu quero fazer isso aí! [...] e eu voltei, quatro anos depois, para a faculdade. E aí sim, e aí eu escolhi fazer aquela faculdade [P7].

Quanto às atividades laborativas, dos oito professores entrevistados, cinco desempenham, atualmente, atividades atreladas à sua área de formação:

Já tenho 15 anos de formação e venho trabalhando sempre como assistente social [...] foi assim que eu adquiri muita, muita experiência, em diversos campos, na prática mesmo [P7].

Eu sou psicanalista clínico [...] exerço atividade clínica para algumas indicações [P6].

[...] eu tenho me dedicado, não de forma exclusiva, à docência, mas a minha maior ênfase está sendo a vida acadêmica [...], mas também não deixei de advogar. [...] 90\%, hoje, da minha atuação, do meu tempo, é direcionado à docência unida aí ao doutorado [P2].

[...] atualmente eu estou na clínica [...] aí eu concilio clínica com a docência [P5].

Advogo já há mais de 10 anos [...]. Amo a advocacia, é a minha paixão! [P1].

É comum encontrarmos professores que conciliam a docência com outra atividade laboral. Isso pode se dar para complemento da renda ou por entenderem que a atuação profissional com a docência forma um importante elo da teoria com a prática. Para Franco (2000), o professor é aquele que privilegia as IES como espaço de trabalho, mas também aquele que se insere em um outro contexto profissional.

Na IES investigada, $68 \%$ dos professores possuem outro vínculo empregatício. Referido percentual advém da soma dos $28 \%$ que trabalham em outras IES e de $40 \%$ que exercem atividades atreladas a sua área de formação.

Estudos como os de Soratto e Nogueira (2013) e Paiva (2010) retratam essas realidades sobre a concomitância de atividades. Muitos docentes de instituições privadas, por não possuírem estabilidade profissional, ou não por não serem contratados sob o regime de tempo integral ou dedicação exclusiva, fazem com que o magistério superior não seja sua atividade principal. Ainda, a docência pode aparecer como ocupação do tempo ocioso do exercício de outra atividade profissional.

Se a aglutinação de atividades pode restringir a dedicação ao magistério a poucas horas semanais, as experiências das vivências oriundas de seus trabalhos são bastante enriquecedoras, proporcionando uma aproximação da vida acadêmica à vivência profissional (LAUXEN, 2014; MANTOVANI; CANAN, 2015), como podemos confirmar nos relatos concedidos por P5 e P1:

[...] esse choque cultural de ter saído da [nome da Universidade] e ter caído nas comunidades mais carentes [...] me fez amadurecer muito como ser humano. Aí eu trago muito essa bagagem, para o meu trabalho na docência hoje. [...] tenho trazido muitas práticas vivenciais para que os alunos sintam como é que na prática funcionam essas terapias. Porque só a teoria fica sem sentido [P5].

[...] eu tenho 10 anos de advocacia, então eu tenho muita história para contar. Tanto histórias engraçadas de vida mesmo, quanto histórias de audiências, de processos diferentes $[\ldots][\mathrm{P} 1]$. 
Atualmente, apenas três entrevistados estão desempenhando somente as atividades ligadas à docência. O professor P4 leciona em outra IES, além da instituição lócus da pesquisa:

[...] toda a minha atividade é ligada à docência. Inclusive [...] eu leciono também pela [nome da Universidade], aqui de Fortaleza. [...] eu estou 100\% na docência hoje [P4].

Tendo discorrido sobre as escolhas da formação dos bacharéis entrevistados, abordarse-á, agora, sobre como foi a escolha ou a decisão de ter a docência como um campo de atuação. A docência no Ensino Superior não chegou de forma uniforme na vida dos entrevistados. Houve quem sempre desejou ser professor, quem recebeu incentivo da mãe que era professora, quem experienciou ministrar aulas em outro nível de ensino, aqueles que se sentiram tocados pelas experiências com alguns professores durante o Ensino Superior, outros cujos professores incentivaram a buscar a docência e, ainda, para alguns, a docência apareceu como oportunidade para ter uma renda.

Os professores P5 e P6 relatam que "ser professor" sempre foi um desejo, um chamado, que desde a infância e adolescência desenvolviam atividades que os aproximavam da docência:

Eu sempre gostei de ensinar [...]. Desde criança. Minha mãe é professora, né? E ela me colocava nessa missão de ensinar para os meus irmãos, assim... ensinar para as provas... e eu sempre gostei muito, principalmente da área de História e Literatura [P5].

No Ensino Médio eu queria ser professor de alguma coisa. [...] Independente de qual profissão eu seguisse, eu seria professor! Fosse eu médico, fosse eu biólogo, fosse eu historiador, fosse eu engenheiro químico, fosse eu psicólogo, que foi a última opção, eu seria professor! Foi uma coisa que eu nunca tive dúvida, sobre ser professor [...] [P6].

Já para a professora P1, a primeira aproximação com a docência foi como professora particular. Segundo a mesma, a docência chegou em sua vida de uma forma despretensiosa, porém encantadora:

[...] foi totalmente despretensioso. Eu queria ganhar dinheiro só para ajudar a comprar um livro, para pagar um congresso, enfim... [...] eu adorava dar aula particular, eu via que eu tinha paciência, eu achava legal aquilo, eu gostava de estudar as coisas para poder ensinar para os alunos [...] [P1].

Para os professores P2, P4 e P8, as vivências e experiências ainda na graduação despertaram o interesse pela docência:

Até o quinto semestre da faculdade eu não tinha ainda uma certeza do que eu queria, se era o Direito e de que forma eu iria trabalhar com o Direito. [...] O ponto inicial foi: eu decidi escrever um artigo para um evento que iria acontecer na Universidade. Então eu conversei com a professora [...], ela aceitou me orientar, e aí foi quando eu escrevi o meu primeiro artigo, e gostei muito. E aí, a partir disso, no semestre seguinte já entrei para a monitoria, e [...] foi o meu primeiro contato com essa experiência docente. A gente ministrava algumas aulas, inclusive junto com a professora, então foi a partir daí [P2].

[...] na faculdade [...] eu tive um problema de depressão [...] e foi na disciplina de saúde mental, que eu fui saber mais sobre essa psicopatologia, e o meu professor era o [nome do professor], eu gostei da maneira dele ensinar, eu gostei da disciplina e ele foi uma das referências que fizeram isso. [...] eu quero ser igual a ele! Eu quero ser um bom professor igual a ele [P4].

No terceiro semestre eu entrei no grupo de pesquisa [...] o coordenador desse laboratório de pesquisa [...] disse: tenho uma bolsa para ti [...]. Ele foi meu orientador. E a partir dessa experiência eu pensei: eu vou ser professor! Porque não foi uma coisa, assim, que eu entrei na graduação querendo, mas digamos que a partir 
do quinto e sexto semestre eu estava saindo de um status de aluno mais disperso para um aluno [...] mais aplicado, mais empenhado. Até por causa da bolsa, do estágio, das muitas experiências, eu decidi ser professor [...] [P8].

Para a professora P3, foram as vivências proporcionadas pelo mestrado e os incentivos do professor orientador que o direcionaram para a docência no Ensino Superior:

[...] diante da questão da pesquisa, das apresentações de trabalhos em eventos, nos congressos, aí você vai familiarizando com essa questão de estar se expressando, de estar conversando com outras pessoas, de estar aprendendo, de estar escutando [...]. Aí eu disse: bem diante dessas circunstâncias, meu currículo está muito bom para ser direcionado para a área da docência. [...] eu tinha indiretamente preparado ele sem saber que eu ia ser uma docente para a área da enfermagem. [...] o meu orientador que indiretamente acendeu: 'Oh, você tem condições, vai lá que você consegue!' [P3].

Apenas para a professora P7 a aproximação com a docência aconteceu depois da sua saída da universidade. Refere, contudo, que os professores reconheciam nela habilidades para lecionar:

[...] eu não pensei na docência, nem passava pela minha cabeça. [...] eu fui monitora [...]. E embora sempre fosse reconhecida pelos professores, essa habilidade, para talvez estar em sala de aula, para desenvolver a docência, eu me afastei desse caminho [P7].

A partir das falas dos professores sobre a docência e sobre ser professor, despertou-se, para este estudo, o interesse em discorrer sobre aquilo que, para muitos, é tido como uma vocação. Buscou-se ancorar as análises e reflexões sobre a vocação nos escritos de Larrosa (2018). Para o autor mencionado, a relação com o que se faz, com aquilo que a pessoa se ocupa, não tem a ver apenas com o que seriam os seus gostos, nem com a questão de talentos, aptidões e capacidades, mas o ‘chamado' da vocação. Esse chamado, que é a descoberta do que interessa a cada um, tem a ver também "[...] como uma maneira de entender a vida e, talvez de entender a responsabilidade com o mundo" (LARROSA, 2018, p. 25).

Continuamos explanando que descobrir uma vocação é descobrir qual é o mundo que nos interessa, é reconhecer o que nos chama atenção, o que nos é relevante, significativo. Mas vai além disso. "Descobrir uma vocação não é apenas averiguar o que gostamos ou o que nos satisfaz, mas o que ela exige de nós. Essa exigência tem a ver com co-responder ao que há aí para aprender, para interpretar, para fazer, para pensar" (LARROSA, 2018, p. 63). A vocação para determinado ofício não se apresenta apenas no começo de uma vida, mas no transcorrer dela. É a partir do exercício do ofício, daquilo que se aprende com ele e para ele, que se revigora a convicção de continuar fazendo o que se faz. Nas palavras do autor, "[...] muitas vezes uma vocação não se descobre a priori, mas a posteriori, não antes, mas depois, não no início, mas no final de uma vida cujos signos e avatares, no entanto, é como se houvessem estado predestinados" (LARROSA, 2018, p. 63).

Tomando o ofício de professor como objeto específico de análise, mais precisamente dos professores entrevistados nesta pesquisa, refere-se que os signos que os levaram a serem professores podem ser identificados em alguns elementos comuns, que os aproximam do universo da docência desde os primeiros contatos com a sala de aula e com os alunos, tais como: "sempre gostei de ensinar", "foi uma coisa que eu nunca tive dúvida", "sempre quis dar aula", "apaixonada" e "realizada". Como retratado nas falas abaixo:

Você entra na sala de aula, começa a dar aula e você decide, é ali que você decide: eu quero fazer isso aqui [...]. Eu sou funcionária pública, mas eu [...] quero terminar os meus dias em sala de aula [...]. Eu não me vejo com 80 anos fazendo uma visita domiciliar, mas eu me vejo com 80 anos dentro de sala de aula, estudando, dando palestras, enfim... [P7]. 
Eu sempre gostei de ensinar, eu sempre achei importante, acho que ensinar e a terapia e o ensino elas estão muito ligadas [...] me sinto realizada na docência [P5].

Contudo, expressões como "totalmente despretensioso", "eu não pensei na docência", "oportunidades", "estabilidade financeira", "convite" podem indicar que a docência aconteceu de forma não planejada.

As pesquisas de Silva e Souza (2017) e Nascimento (2017), de forma semelhante, referem que para muitos professores, o exercício docente não aconteceu de forma planejada, tendo prevalecido aspectos como desemprego, busca por estabilidade, insatisfação em outros trabalhos, demonstrando que ser professor não era objeto de desejo dos profissionais pesquisados.

É interessante observar que muitos dos professores entrevistados passaram a exercer ou a vislumbrar a docência em decorrência de suas atividades de monitoria, de pesquisa, como alunos da pós-graduação, pelos incentivos dos professores orientadores ou ainda, pela figura de alguns docentes, que foram peças importantes para despertar o chamado para a docência:

[...] o pontapé inicial foi exatamente a experiência da monitoria, foi quando eu percebi que eu gostava da docência [P2].

[...] eu era monitora, sempre gostei de dar aula, eu sempre quis dar aula [...] [P1].

[...] eu fiz monitoria, inclusive alguns professores falavam que durante as apresentações de seminário eu falava muito bem e isso fez com que eu tivesse essa paixão pela docência [P4].

[...] o professor no mestrado disse [...]: disciplina tal e tal você vai ministrar [...] e foi uma experiência riquíssima para mim. [...] E desse dia em diante, desde o mestrado para cá, eu gostei e foi! [P3].

Os programas de monitoria ofertados em diversas IES se apresentam como uma oportunidade para o desenvolvimento acadêmico, possibilitando a ampliação de conhecimentos na área de realização da monitoria, oportunizando aos discentes monitores a iniciação na atividade de docência, podendo despertar o interesse por este espaço de atuação profissional. Analisando as falas concedidas pelos professores entrevistados percebemos que as atividades de monitoria foram potencializadoras para suas escolhas em profissionais no tocante à docência.

Para que pudessem lecionar, ou se sentissem mais preparados para o exercício da docência, alguns docentes trilharam determinados caminhos, a partir da graduação. Ingressar em programas de mestrado foi a escolha da maioria:

\begin{abstract}
[...] muitos dos meus professores eram mestres e doutores e eles sempre falavam da importância de se qualificar. [...] quando eu fiz a monitoria, eu coloquei na minha cabeça de fazer a especialização, um mestrado e também se possível o doutorado. [...] o caminho [...] era me qualificar mais, para que eu pudesse estar me especializando em dar aula, em ser docente. Então, foi esse o caminho que eu fiz [P4].
\end{abstract}

De acordo com Nascimento (2017), é perceptível a importância que os professores concedem à pós-graduação para a docência universitária, considerando-a como um caminho que conduz os bacharéis para o exercício da profissão docente.

Para Masetto (2012), seguindo o mesmo entendimento, os cursos de pós-graduação, sejam lato ou stricto sensu, são os mais procurados pelos professores que atuam no Ensino Superior. A procura ocorre, tanto pela exigência das legislações e das IES, por professores pósgraduados, como também por ser um espaço para a sua formação continuada.

Para o professor P2, cursar a especialização e o mestrado o fez entender que poderia então atuar como professor do Ensino Superior: 
Quando eu terminei a graduação eu comecei a advogar, mas surgiu a oportunidade de fazer uma especialização em Direito de Família. Gostei e como eu estava interessado pela pesquisa, eu decidi: vou entrar para o mestrado. [...]. Então [...] como eu dei continuidade, eu vi por bem, já que eu segui nessa linha, eu vou também buscar aqui a iniciar a docência universitária [P2].

Contudo, nem sempre os programas de pós-graduação dão conta de formar seus alunos para a docência. A maior ênfase concedida é para a formação do pesquisador, e mesmo sendo a pesquisa importante para a docência, aquela se volta mais para o aprofundamento de conteúdos e descobertas de aspectos de determinadas áreas do conhecimento, deixando, por vezes, de trabalhar a formação do aluno para a docência (MASETTO, 2012).

O Professor P6 traz essa inquietação na sua fala:

Os meus professores de mestrado e doutorado [...] são pessoas com muito conhecimento e zero didática, a maioria deles. Porque eles não passam por esse processo de formação para ser docente, passa pelo processo de formação para ser pesquisador [...]. Alguns docentes são mais pesquisadores do que professores, alguns docentes são mais professores do que pesquisadores. Eu hoje me encontro num meio termo [P6].

Os escritos de Cunha (2000) reforçam o entendimento citado. Para a autora, o modelo de formação que vem presidindo o magistério superior tem sua base principal na pesquisa. Imagina-se a docência enquanto atividade científica, em que basta apenas o domínio de conhecimento específico e o instrumental para a produção de novas informações para que seus objetivos sejam cumpridos. Contudo, a fala de um professor indica a lacuna deixada na formação, por determinados cursos de pós-graduação:

[...] eu não sabia de antemão, dos desafios de ser professor. Porque uma coisa é você ver os outros ensinar, você ver os professores ensinar, outra coisa é você ser professor. Aí que você vai saber realmente dos desafios que a docência demonstra no dia a dia [P4].

Essa fala permite inferir um certo despreparo para o exercício da docência no Ensino Superior. Para Cunha e colaboradores (2006), essa lacuna na formação é retratada na frase "dormi aluno e acordei professor". Muitos professores têm uma imensa bagagem de conhecimentos nas suas áreas de pesquisa e de atuação profissional, mas nunca se questionaram sobre o que significa ser professor. Tal despreparo pode ressoar negativamente nos processos de ensino e de aprendizagem.

A formação docente tem se apresentado como uma dificuldade de muitos professores, principalmente daqueles que advêm dos cursos de bacharelado e que, no período em que cursaram a pós-graduação, notadamente mestrado e doutorado, não participaram de formações voltadas para atuar como professor. São profissionais cognominados de "bacharéis-docentes", que mesmo sem uma formação didático-pedagógica têm exercido a profissão (OLIVEIRA; SILVA, 2012).

São esses professores bacharéis, com formação advinda dos cursos stricto sensu, que têm espaço privilegiado nas contratações por parte das IES, pois atendem às exigências constantes nas legislações que regulam e avaliam essas instituições. Contudo, a formação nesses cursos de pós-graduação se caracteriza por estudos para a formação do pesquisador, mostrandose insuficiente para enfrentar os desafios que os processos de ensinar e de aprender atual exigem.

O que se tem percebido e vivenciado é um distanciamento ou uma total ausência dessa formação, seja nos relatos dos entrevistados desta pesquisa, seja pelas pesquisas realizadas por 
outros autores, que partilham dessa realidade. Foi consenso entre os professores entrevistados a ausência de qualquer conteúdo, durante a graduação, que versasse sobre práticas pedagógicas:

Na graduação não, sobre práticas pedagógicas [P4].

Eu não cheguei a ter disciplina sobre isso, no bacharelado não tem disciplina sobre isso e nem no mestrado também [...] [P6].

Outros professores relatam que suas aproximações com as práticas pedagógicas aconteceram com o exercício da monitoria/estágio docente:

[...] na disciplina de estágio docente. [...] eu era como monitor da disciplina de psicologia social. Eu cheguei a dar duas aulas [...] com o meu orientador na sala. Duas aulas sozinho [P6].

[...] eu fiz o estágio de docência, digamos que é algo mais aproximado de práticas pedagógicas [...] no mestrado. [...] dei algumas aulas para os alunos das Ciências Sociais, mas a maioria das vezes eu acompanhava a professora da disciplina e não tinha um espaço reflexivo, um espaço de discussão era algo muito mecânico então eu nem considerei como uma prática pedagógica, mas no currículo tinha essa proposta. Mas é algo assim que pouco me agregou [P8].

Para o professor P2, as experiências, ainda que esparsas, o ajudaram a se sentir preparado para a docência:

[...] se eu não tivesse tido essa formação tanto numa disciplina teórica, de Didática do Ensino Jurídico, como também a experiência prática, na disciplina de Estágio à Docência, eu realmente acho que eu não estaria preparado, [...] eu não estaria [...] com a confiança para atuar enquanto docente [P2].

Já para P5, a ausência de experiências e contato com práticas pedagógicas dificultou seu exercício da docência:

[...] não ter experienciado, não ter tido uma disciplina que me orientasse nesse sentido, fez falta, sabe, no começo [P5].

O seu relato é seguido de outros relatos docentes, que iniciaram ministrando aulas sem uma sólida formação pedagógica. A falta de formação e as dificuldades para lecionar podem ser visualizadas nas expressões "me virar", "na marra", "muito intuitiva", "no feeling" e "no sentimento", demonstrando, também, um processo, por vezes, solitário:

A minha experiência pedagógica foi a minha primeira experiência de emprego [...] uma turma que era conhecida como furacão e eu entrei no olho furacão e eu tive que me virar. E aí eu fui adquirindo digamos assim uma prática pedagógica, uma experiência pedagógica, como o pessoal diz 'na marra' [P8].

[...] eu percebi que o jeito que eu ensinava era mais fácil, as pessoas entendiam com mais facilidade, elogiavam a didática. Muito intuitiva, porque eu nunca tinha estudado nada sobre didática ou coisas do tipo [...] [P6].

Eu fiz também na faculdade uma cadeira de oratória, uma cadeira de lógica, então essas cadeiras acabaram ajudando a montar meio que esse perfil de professor que eu queria ser. Que eu não tinha essa formação, mas assim [...] minha mãe é professora, minha mãe é formada em Letras, ela deu aula muitos anos [...] então eu tinha isso, eu convivi. [...] O que eu tinha de docência propriamente era isso, mas fora essas cadeiras e essa experiência pessoal, não fiz nada academicamente falando, voltado para docência. Foi mais no feeling mesmo, no sentimento [P1].

Para Gil (2012, p. 9), muitos professores aprenderam seu ofício como os antigos aprendiam: fazendo. Segue explanando que os professores universitários não recebem preparação específica e, mesmo ao longo de suas vidas profissionais, são poucas as 
oportunidades de participarem de formações sobre os métodos de ensino e avaliação da aprendizagem: "A pedagogia fica, portanto, ao sabor dos dotes naturais de cada professor".

Ademais, a busca pela pós-graduação também apareceu, nas falas dos professores, como uma possibilidade de lecionar e conseguir uma estabilidade financeira:

[...] eu pensei que se eu fizesse o mestrado eu poderia estar melhorando de vida [...]. Eu queria, na época que eu fiz o mestrado, na época que eu fiz a especialização, melhorar muito o meu currículo [...] entrar no mestrado seria um caminho, digamos, mais fácil para uma estabilidade financeira. Fiz o mestrado na perspectiva de dar aula e dando aula conseguiria estudar para concursos públicos e eu poderia ter dois caminhos: que era fazer um doutorado para agregar mais valor ao meu currículo e tentar concurso público, realizando um objetivo inicial, um objetivo que muitos professores almejam, que é dar aula tendo estabilidade [P8].

Foram poucos os relatos que caminharam na contramão dos anteriormente expostos, em que o desejo e a necessidade de cursar uma pós-graduação não aconteceu durante a formação. Para P5 e P7, o caminho trilhado foi primeiro o da experiência profissional na área de formação, para depois, então, pensar a docência:

Eu não vou dizer que eu me preparei durante a minha graduação para a docência. [...] de participar de grupos de estudos, de publicar artigo e participar de muitos congressos, já pensando no mestrado. Não eu não pensei no mestrado. [...] Primeiro eu queria saber como era na prática para depois eu querer ensinar sobre isso [...] [P5].

[...] os meus professores diziam assim, porque eu fui monitora [...] 'Ah, você tem que fazer isso'; 'Ah você tem que ir para o mestrado'. E eu dizia: como é mestrado? A professora dizia: 'é continuar estudando' e eu digo: não, eu quero é ir trabalhar. 'Mas recebe dinheiro, tem a bolsa' [fala da professora]. Não, mas eu não quero receber dinheiro não, eu quero ir lá no campo, fazer o que eu fazia no estágio, atender as pessoas [P7].

Para alguns docentes, a oportunidade de lecionar apareceu quando ainda estavam cursando a pós-graduação ou logo após a sua conclusão, como podemos verificar nas falas a seguir:

[...] eu iniciei a dar aula numa faculdade privada daqui de Fortaleza ainda fazendo o mestrado, mas não era contratação fixa, eram aulas avulsas. [...] E aí eu fui pegando o gosto em dar aula. Dessa faculdade [...] eu fiz o teste de seleção para professor substituto da [nome da Universidade]. [...] e fui convidado [...] para ir para a [nome da Instituição lócus da pesquisa] [P6].

[...] eu comecei a buscar as possibilidades de ministrar aula e foi quando eu consegui logo no final do meu mestrado ingressar na [nome da Instituição lócus da pesquisa], onde estou até o presente momento [P2].

[...] assim que eu terminei o mestrado [...] surgiu o convite de um colega, exatamente para Direito do Trabalho, que era minha área de atuação [...]! E aí ele conseguiu para mim uma entrevista e eu comecei a dar aula [...] [P1].

Em um breve resumo, elucida-se que o caminho percorrido até a sala de aula envolveu escolhas, oportunidades e desafios para os professores pesquisados. A escolha pela área de formação, bem como pela docência, não aconteceu com uniformidade para todos. As aproximações com a docência vieram durante a graduação, a pós-graduação, com o exercício da monitoria, da pesquisa, do desejo em ser igual a determinado professor, bem como dos incentivos de docentes e de familiares. A busca pela pós-graduação foi almejada por todos, ainda que alguns não tenham conseguido iniciar o mestrado logo após a conclusão da graduação e/ou da especialização. No entanto, referiram que as disciplinas das especializações e dos mestrados lhes trouxeram conhecimentos específicos de área, mas pouco contribuíram para a sua formação docente. 
Na pesquisa realizada por Nascimento (2017), a autora diz que as regras de ingresso de professores no Ensino Superior privado não acontecem de forma rigorosa. Geralmente acontece mediante convite, com mais oportunidades em períodos de criação de cursos, ainda que os professores não apresentem experiência com a docência. Algo semelhante ocorreu com os professores participantes desta pesquisa. Como são docentes de IES privadas, a docência chegou através de convite, para a maioria, sendo que muitos não passaram por nenhum tipo de seleção. Mesmo em meio aos desafios, reconhecem e têm a docência como uma área de atuação revestida de encantos, possibilidades e realizações. Assim, os professores investigados vão trilhando a docência sem uma sólida formação pedagógica e baseando sua prática nas suas vivências enquanto alunos e a partir das experiências obtidas no contexto da sala de aula.

\section{Considerações finais}

A docência no Ensino Superior é marcada por desafios, dentre os quais podemos citar a ausência ou pouca formação didática e pedagógica dos professores. Os cursos de pós-graduação lato sensu geralmente formam seus alunos para uma área específica da sua formação inicial. Já os cursos stricto sensu têm um enfoque maior sobre a pesquisa, destinando poucas ou nenhuma disciplina que fomentem a formação para a docência.

A pesquisa nos permitiu verificar que muitos professores, mesmo sem uma formação pedagógica, iniciaram ministrando aulas sem um processo reflexivo, adotando uma ação embasada no modelo tradicional de sua formação. Os professores relataram que as dificuldades em adotar outras estratégias de ensino decorrem, principalmente, da lacuna de suas formações.

O estudo possibilitou, ainda, não só reconhecer os desafios que os bacharéis encontraram no processo de constituição da docência, mas em cultivar a reflexão e buscar outros caminhos para suas formações. E despertou também o interesse em seguir perguntando, estudando, pesquisando essas e outras realidades, procurando alternativas que tornem o Ensino Superior e a formação docente e discente como propulsoras de uma transformação social.

Analisar cada contexto, considerando as especificidades institucionais é tarefa primordial para reconhecer a realidade docente, e então, propor ações interventivas visando preencher as lacunas existentes no processo de formação dos professores e viabilizando a construção de uma prática pedagógica capaz de transformar as práticas profissionais e, consequentemente, a qualidade do ensino ofertado.

Destaca-se, como fruto desta investigação, algumas indicações de ações que poderão ser adotadas pela IES pesquisada, bem como por outras instituições, no tocante ao suporte para a formação continuada dos seus docentes: oferta de capacitações e formações; incentivo para cursar mestrado e doutorado; promoção de espaços de reflexão da própria prática, trabalhando questões não manifestas na formação dos docentes, como práticas pedagógicas e estratégias de ensino.

A formação continuada para os professores se apresenta como instrumento valioso para ressignificação das suas ações e práticas pedagógicas. Ela favorece a atuação docente, ao passo que proporciona novos conhecimentos e desenvolve competências que auxiliarão na sua atuação frente aos desafios contemporâneos, e que também transformarão sua prática em sala de aula, junto aos seus alunos. Assim, a promoção de espaços de formação continuada poderá contribuir para o aperfeiçoamento da atividade educativa, através de processos de ensino e de aprendizagem mais significativos, que ressoem positivamente nas atuações profissionais de professores e alunos. 


\section{Referências}

ALMEIDA, Maria Isabel de. Formação do professor do ensino superior: desafios e políticas institucionais. São Paulo: Cortez, 2012.

ANASTASIOU, Léa das Graças Camargos. As bases teórico-metodológicas da educação de adultos e os desafios da metodologia ativa nos cursos de graduação. In: MARTINS, Ana Karenina Azevedo (org.). Metodologias ativas de aprendizagem no ensino superior: relatos e reflexões. São Paulo: Intermeios, 2015.

ANASTASIOU, Léa das Graças Camargos. Profissionalização continuada do docente da educação superior: desafios e possibilidades. Olhar de Professor, v. 8, n. 1, p. 9-22, 2005. Disponível em: https://www.revistas2.uepg.br/index.php/olhardeprofessor/article/view/1424. Acesso em: 12 fev. 2019.

ANASTASIOU, Léa das Graças Camargos. Profissionalização continuada: aproximações da teoria e prática. In: BARBOSA, Raquel Lazzari Leite (org.). Trajetórias e perspectivas da formação de educadores. São Paulo: Editora UNESP, 2004.

BARDIN, Laurence. Análise de conteúdo. São Paulo: Edições 70, 2011.

BRASIL. Constituição da República Federativa do Brasil: promulgada em 5 de outubro de 1988. Disponível em: http://www.planalto.gov.br/ccivil_03/constituicao/constituicao.htm. Acesso em: 18 set. 2019.

BRASIL. Lei $n^{\circ}$ 9.394. Estabelece as diretrizes e bases Ciência e Educação da educação nacional, de 20 de dezembro de 1996. Presidência da República. Brasília, DF. Disponível em: http://www.planalto.gov.br/CCIVIL_03/Leis/L9394.htm. Acesso em: 20 out. 2019.

CUNHA, Ana Maria de Oliveira; BRITO, Taita Talamira Rodrigues; CICILLINI, Graça Aparecida. Dormi aluno (a)... Acordei professor (a): interfaces da formação para o exercício do ensino superior. Políticas de Educação Superior, p. 1-15, 2006. Disponível em: http://www.anped.org.br/sites/default/files/gt11-2544-int.pdf. Acesso em: 20 ago. 2019.

CUNHA, Maria Isabel. Ensino como mediação da formação do professor universitário. In: MOROSINI, Marília Costa (org.) Professor do ensino superior: identidade, docência e formação. Brasília: Instituto Nacional de Estudos e Pesquisas Educacionais, 2000.

FRANCO, Maria Estela Dal Pai. Comunidade de conhecimento, pesquisa e formação do professor do ensino superior. In: MOROSINI, Marília Costa. (org.) Professor do ensino superior: identidade, docência e formação. Brasília: Instituto Nacional de Estudos e Pesquisas Educacionais, 2000. p. 61-73.

GIL, Antônio Carlos. Didática do ensino superior. São Paulo: Atlas, 2012.

GIL, Antônio Carlos. Métodos e técnicas de pesquisa social. 7. ed. São Paulo: Atlas, 2019. 
LARROSA, Jorge. Esperando não se sabe o quê: sobre o ofício de professor. Belo Horizonte: Autêntica, 2018.

LAUXEN, Sirlei de Lourdes. A docência no ensino superior: saberes e práticas. Eventos Pedagógicos, v. 5, n. 3, p. 138-151, 2014. Disponível em: http://sinop.unemat.br/projetos/revista/index.php/eventos/article/view/1550. Acesso em: 02 ago. 2019.

LIRA, Daiane; SPONCHIADO, Denise Aparecida Martins. A formação pedagógica do profissional docente no ensino superior: desafios e possibilidades. Revista Perspectiva, v. 36, n. 136, p. 7-15, 2012. Disponível em:

http://www.uricer.edu.br/site/pdfs/perspectiva/136_297.pdf. Acesso em: 01 set. 2019.

MANTOVANI, Isabel Cristina de Almeida; CANAN, Silvia Regina. Política de formação para professores do ensino superior e qualidade de ensino: um estudo sobre o programa pedagogia universitária como possibilidade de qualificação docente na perspectiva pedagógico-didática. Revista Internacional de Educação Superior, v. 1, n. 2, p. 136-148, 2015. Disponível em:

https://periodicos.sbu.unicamp.br/ojs/index.php/riesup/article/view/8650525. Acesso em: 03 ago. 2019.

MARCONI, Marina de Andrade; LAKATOS, Eva Maria. Metodologia científica. 7. ed. São Paulo: Atlas, 2017.

MASETTO, Marcos Tarciso. Competência pedagógica do professor universitário. 2. ed. São Paulo: Summus, 2012.

MINAYO, Maria Cecília de Souza. O desafio da pesquisa social. IN: MINAYO, Maria Cecília de Souza (org.). Pesquisa social: teoria, método e criatividade. 34. ed. Petrópolis: Vozes, 2015.

MOROSINI, Marília Costa. Docência universitária e os desafios da realidade nacional. In: MOROSINI, Marília Costa (org.). Professor do ensino superior: identidade, docência e formação. Brasília: INEP, n.2, 2000. p.11-21. Disponível em: http://bibliotecadigital.puccampinas.edu.br/services/e-books/D_professor_ensino_superior.pdf. Acesso em: 15 jul. 2019.

NASCIMENTO, Vivianne Souza de Oliveira. O bacharel e a docência: as influências da pósgraduação na carreira profissional. Holos, v. 2, p. 280-289, 2017. Disponível em: http://www2.ifrn.edu.br/ojs/index.php/HOLOS/article/view/5738. Acesso: 12 jan. 2019.

OLIVEIRA, V.S.; SILVA, R. F. Ser bacharel e professor: dilemas na formação de docentes para a educação profissional e ensino superior. Holos, ano 28, v. 2, p.193-205. 2012. Disponível em: http://www2.ifrn.edu.br/ojs/index.php/HOLOS/article/download/913/542. Acesso em: 20 jan. 2019.

PAIVA, Giovanni Silva. Recortes da formação docente da educação superior brasileira: aspectos pedagógicos, econômicos e cumprimento de requisitos legais. Ensaio: Avaliação e Políticas Públicas em Educação, v. 18, n. 66, p. 157-173, 2010. Disponível em: http://www.scielo.br/pdf/ensaio/v18n66/a09v1866.pdf. Acesso em: 02 set. 2019. 
SILVA, Silvia Helena dos Santos Costa; SOUZA, Francisco das Chagas Silva. Bacharéis que se tornam professores: inserção e prática profissionais de engenheiros no ensino superior. Holos, v. 5, p. 197-213, 2017. Disponível em: http://www2.ifrn.edu.br/ojs/index.php/HOLOS/article/view/4033. Acesso em: 22 jan. 2019.

SORATTO, Fernanda Peres; NOGUEIRA, Eliane Greice Davanço. A construção da docência no ensino superior: da formação inicial à continuada do professor do curso de direito.

Interfaces da educação, v. 4, n. 10, p. 92-108, 2013. Disponível em:

https://periodicosonline.uems.br/index.php/interfaces/article/view/529. Acesso em: 03 ago. 2019.

Recebido em agosto de 2021.

Aprovado em outubro de 2021. 